\title{
Algo más sobre el Meridiano editorial hispanoamericano (1927-1928)
}

\section{Something more about the Meridiano editorial hispanoamericano (1927-1928)}

\begin{abstract}
Resumen
El trabajo se propone revisar el contexto editorial del artículo de Guillermo de Torre "Madrid meridiano intelectual de Hispanoamérica" en conexión con las características del proyecto de La Gaceta Literaria de Madrid, órgano en que se publicó en 1927. Esa revisión permite incorporar un conjunto de entrevistas realizadas por Guillermo de Torre -corresponsal en Buenos Aires del periódico español- a los editores porteños más destacados de esos años. Éstas constituyen un momento destacado, aunque menos transitado de las discusiones condensadas en aquel editorial del 1927.
\end{abstract}

Palabras claves

Meridiano editorial, Guillermo de Torre, La Gaceta Literaria, relaciones editoriales.

\begin{abstract}
The work proposes to review the editorial context of Guillermo de Torre's article "Madrid meridiano intelectual de Hispanoamérica" in connection with the characteristics of the project of La Gaceta Literaria de Madrid, the body in which it was published in 1927. This revision allows the incorporation of a set of interviews conducted by Guillermo de Torre -corresponsal in Buenos Aires of the spanish newspaper- to the most outstanding Buenos Aires editors of those years. These constitute a highlight, although less traveled, of the discussions condensed in that editorial of 1927.
\end{abstract}

Keywords 
Me propongo en estas páginas volver a mirar la polémica que provocó en 1927 el editorial de Guillermo de Torre, "Madrid meridiano intelectual de Hispanoamérica", publicado en la octava entrega de La Gaceta Literaria (19271932), ${ }^{1}$ dando cuenta del modo en que el periódico procesó en sus páginas el contexto de ese debate, cuyo centro eran las posibilidades de expansión de la industria editorial española, como parte de una política del libro. En ese sentido, los jóvenes vanguardistas responsables de $L G L$ articularon una posición que volvía irrelevante la oposición arte-lucro/ arte-éxito proponiendo una modernidad centrada en la necesidad de difusión de la producción editorial que -afirmabandebía ir más allá de los límites del "gremio letrado" e interesar a "la masa lectora, al presunto público de librería". LGL se pensó como un agente particularmente vital en ese proceso divulgador no solo de libros y autores, y desde esa mirada, interpeló a los escritores poniéndolos frente a los problemas específicos del mercado del libro en expansión, como parte inescindible de su quehacer literario. De ese modo, se diferenció explícitamente de las revistas literarias, a las que circunscribió al terreno acotado de los debates críticos y estéticos para subrayar su rasgo menos sectario como periódico de letras, género al que definió y caracterizó en numerosas ocasiones.

La polémica desatada en torno del artículo de Guillermo de Torre en $L G L$ constituye un punto en la rearticulación de las relaciones culturales y editoriales entre España y sus ex colonias. ${ }^{2}$ La crítica argentina ${ }^{3}$ se ha ocupado del análisis de

${ }^{1}$ En adelante $L G L$.

${ }^{2}$ El punto inicial del debate se vincula, justamente con las significaciones implicadas en el modo de referirse al continente americano. En ese sentido, el escrito de Guillermo de Torre impugna la denominación "América Latina" para afirmar como únicos "nombres lícitos y justificados para designar globalmente [...] a las jóvenes repúblicas de habla española, que los de Iberoamérica, Hispanoamérica o América española. Especialmente, cuando se aluda a intereses espirituales, a relaciones literarias, intelectuales o de cultura”. LGL. Año 1, no 8, abril. 1927:1

${ }^{3}$ La polémica ha sido analizada en relación con las posiciones desplegadas en la revista Martín Fierro (1924-1927). En la Bibliografía de este trabajo se consignan las contribuciones de Beatriz Sarlo, Ángela Di Tulio, Celina Manzoni, Sara Bosoer. 
la polémica que desató el escrito de Guillermo de Torre en el terreno local, sobre todo en relación con las discusiones en torno de la llamada "cuestión del idioma", que en la revista argentina Martín Fierro se moduló seria o jocosamente como independencia lingüística. ${ }^{4}$ No obstante, las implicaciones de esa polémica en $L G L$ van más allá de los intercambios entre gacetilleros y martinfierristas. En ese sentido, Alejandrina Falcón ha destacado que "lejos de ser un acontecimiento aislado, el editorial de Guillermo de Torre" constituye un efecto discursivo más de una "serie discursiva global" (Falcón 50) cuyas ideas directrices remarcaban la función del libro como vehículo de acercamiento cultural entre España y América, y reclamaban la legitimidad histórica de España sobre la conquista de los mercados del libro (Larraz 22-24). Por su parte Mechthild Albert (339) ha estudiado el proyecto de La Gaceta Literaria destacando su vocación por situarse en un contexto internacional y ha reparado en el "concepto editorial" de la publicación expresado en su definición como "periódico de las letras". ${ }^{5}$ Albert se focaliza en los modos en que $L G L$ intenta construir diversas comunidades imaginarias transnacionales, remarcando el carácter problemático de la idea de una comunidad ibérica transatlántica, que como muestran los lineamientos del editorial de Guillermo de Torre, se resuelve tanto simbólica como materialmente a favor de la posición dominante de España sobre "Iberoamérica" (Albert 341). Como momento notorio, aunque menos transitado de la cuestión meridiana, y en el marco "del proceso de internacionalización secular" (Fernández Moya 11-12) ${ }^{6}$ que caracterizó a la

${ }^{4}$ La revista Martín Fierro publicó una serie de respuestas a "Madrid meridiano ...". Lo hizo en la entrega de junio-julio de 1927 y en la de agosto-noviembre de ese mismo año. Quienes contestaron fueron: Nicolás Olivari, Jorge L. Borges, Pablo Rojas Paz, Santiago Ganduglia, Lizardo Zía, Raúl Scalabrini Ortiz, Idelfonso Pereda Valdes; Ricardo Molinari, Carlos Mastronardi, Leopoldo Marechal, Evar Méndez, Eduardo González Lanuza, Raúl González Tuñón; el Vizconde Lascano Tegui, Mario Flores, Francisco Luis Bernárdez, Enrique González Trillo.

${ }^{5}$ Como se verá en el parágrafo siguiente, esta definición corresponde a José Ortega y Gasset y es fundamental para la comprensión del proyecto de $L G L$ como contexto del debate meridiano.

${ }^{6}$ Según Fernández Moya "[p]odemos distinguir dos modelos empresariales en esta primera fase de internacionalización. El primero sería el de las editoriales familiares, principalmente catalanas, de pequeño tamaño que desembarcaron en los mercados americanos a finales del siglo XIX. Un segundo modelo lo constituirían las dos únicas editoriales que contaban con capacidad financiera y que se apoyaron en ella para iniciar el proceso de internacionalización: Espasa Calpe y la CIAP. Podríamos considerar un tercer grupo de editoriales que no afrontaron directamente un proceso de 
industria editorial española desde finales del siglo XIX, propongo pensar también la serie de entrevistas que, como corresponsal de $L G L$, realizó en 1928 Guillermo de Torre a los editores más destacados de Buenos Aires de ese momento. Esas entrevistas se organizaron según las claves del editorial de 1927 que condensó algunos de los fundamentos de la intervención de $L G L$, legibles en su "concepto editorial" que involucra los textos y la dimensión organizativa del periódico. En efecto, el tipo de secciones que compusieron la revista y las diversas notas previas y posteriores al escrito de Guillermo de Torre, fueron medulares para llevar adelante una política editorial específica respecto del libro español en América y del libro americano en España. En estas entrevistas, las respuestas de los editores se desplazan de la cuestión lingüística para pensar las condiciones materiales y las dificultades de su actividad que, según los casos, definieron acentuando su "amor a la literatura y la búsqueda de beneficio" (Bourdieu 242). Del lado de Guillermo de Torre se proponen como estrategia de conocimiento de un mercado futuro, a la vez que bosquejan y sondean la viabilidad del comercio librero fundado en la creación de una política de distribución con centro en Madrid. El trabajo intenta reponer un vínculo no suficientemente destacado entre el proyecto editorial de $L G L$, las problemáticas que el editorial de Torre condensa y las entrevistas, estas últimas como parte de un archivo meridiano todavía en construcción.

\section{La Gaceta Literaria: sus imperativos como "periódico de las letras"}

A fines del siglo XIX algunos actores españoles señalaban "las insuficiencias del comercio exterior del libro español y la escasa competitividad de sus editores frente a los alemanes y franceses”, quienes, según Fernando Larraz, siguieron concentrando "elevadas cuotas de los mercados americanos durante los primeros tres decenios del siglo XX" (15). Esta situación, agudizada por las

internacionalización, sino que cedieron sus fondos para que los distribuyese en América Latina una editorial de mayor tamaño" (11-12). 
desventajas de las técnicas de impresión españolas con respecto a otras industrias editoriales europeas, por las numerosas ediciones piratas americanas, o por la falta y luego el incumplimiento de las leyes de protección de la propiedad intelectual, hizo que las ventajas que a priori ofrecía la posesión de una lengua común, no tuvieran su correlato en el comercio de libros con América -tanto del libro de autor americano hecho en España como del libro de autor español. A esto había que agregar, según Martínez Rus, la carencia de un análisis específico sobre los gustos de los lectores americanos por parte de los editores españoles, más allá de las declaraciones de hermandad o comunidad hispanoamericana propias de los discursos fundantes del hispanismo a fines del siglo XIX. ${ }^{7}$

El primer número de $L G L$ se publicó en ese contexto de búsqueda de expansión comercial de los mercados, en enero de 1927, bajo la dirección de Ernesto Giménez Caballero y con Guillermo de Torre como secretario de redacción. ${ }^{8}$ Desde el comienzo y más allá de tratarse de un proyecto realizado por jóvenes, $L G L$ no vinculó su aparición con una estética sino con una política cultural, específicamente editorial cuyo objetivo fue promover el conocimiento mutuo de las letras ibéricas y americanas según reforzaba su subtítulo: ibérica, americana e internacional. En "Salutación" manifestaba el carácter editorial de sus propósitos cuando se definía como "periódico de las letras", un "nuevo organismo intelectual creado por la posguerra, en su afán multitudinario de popularizar la alta cultura de la "Revista" con el fin de "acercar eficazmente autores, editores y lectores" (LGL. Año1, no 1, enero. 1927:1). ${ }^{9}$

${ }^{7}$ Ana Martínez Rus explica que la vocación americanista "nació ligada a proyectos políticos regeneracionistas y a intereses económicos catalanes. [...] La intención mercantil y cultural culminó con la celebración del Congreso Nacional del Comercio de Ultramar en 1923, donde el libro español y su difusión ocupó un lugar destacado por la importancia económica del mismo en aquellos vastos mercados de habla hispana, y por su carácter de mercancía de penetración, facilitando la apertura como incentivo directo a otros productos comerciales del país" (1024).

${ }^{8}$ Para una historia de los cambios internos en el periódico se puede consultar la presentación de $L G L$ en la hemeroteca digital Proyecto filosofía en español http://www.biblioteca.org.ar/Libros/fe/m013.htm

${ }^{9}$ Decían: “Su afirmación en el presente es de carácter editorial. Existía en el mundo (Europa), desde hace unos pocos años, el tipo del 'periódico de las letras', nuevo organismo intelectual creado por la posguerra, en su afán multitudinario de popularizar la alta cultura de la 'Revista', y de acercar eficazmente autores, editores y lectores. Francia, Italia, Inglaterra, Alemania poseíanlo ya. Faltaba 
José Ortega y Gasset, quien desde 1923 llevaba adelante el proyecto editorial de la Revista de Occidente (revista y sello editor), ${ }^{10}$ firmaba "Un periódico de las letras", escrito que reforzaba el programa de las acciones futuras de $L G L$, la cual, como la publicación de Ortega, intentaría conjugar su labor con la edición de libros, llevando adelante una biblioteca ibérica. "1 "Salutación" y el escrito de Ortega utilizaron el repertorio semántico del viaje de ultramar para caracterizar el proyecto y sus objetivos. ${ }^{12}$ La caracterización que hacía Ortega de $L G L$ como

nuestra área hispánica. La Gaceta Literaria intenta hoy cuajar ese hueco ibérico e incorporarse a la tipicidad mundial, europea". $L G L$.Año1, no 1, enero. 1927:1.

Ya en 1929, y por razones económicas, $L G L$ pasó a depender de la CIAP (Compañía IberoAmericana de Publicaciones, S.A.). Esto reforzaría el rasgo editorial del proyecto del periódico. Según se explica en el texto de presentación de la $L G L$ de http://www.filosofia.org/hem/med/m013.htm, la CIAP era un grupo "controlado por el banquero Ignacio Bauer, asesorado por el monárquico, conspirador y místico Pedro Sáinz Rodríguez, que fue impuesto como co-director. En sus inicios, en 1927, La Gaceta se había financiado con 10.000 pesetas aportadas por un grupo de personalidades liberales, que más tarde estarían ligadas a la caída de la monarquía y el advenimiento de la república: Nicolás María de Urgoiti, Gregorio Marañón, Ángel Ossorio y Gallardo, duque de Maura, José Antonio de Sangróniz, José Félix de Lequerica, José María de Areilza, Ramón de Basterra o Gustavo Gili. Era natural que el acercamiento al fascio que se había producido en el inspirador del proyecto hiciese desconfiar a mecenas tan liberales (lo mismo hubiese sucedido si la prolongación natural de tales vanguardismos hubiera sido el comunismo). Giménez Caballero logró que CIAP, el mismo año de la convulsión universal del capitalismo, devolviese a los mecenas iniciales su capital; pero al perder el control que le suponía ser el impresor, quedaba en manos de quienes, proclamada la República, lucharían por una restauración católica y monárquica". http://www.filosofia.org/hem/med/m013.htm

${ }^{10}$ Jesús Martínez Martín (2001) afirma que en el siglo XX se concluyó en España el proceso de depuración y definición de la categoría de editor, diferenciándose de las figuras de libreros e impresores. Como caso testigo de un tipo de editor profesional que enfatiza el papel intelectual de los editores -fundado en la creencia de las clases medias intelectuales en la "misión civilizadora y europeísta de la regeneración del país"-, cita las experiencias editoriales de Renacimiento y Revista de Occidente. Se trata de proyectos más preocupados "por la producción intelectual y la extensión cultural" antes que el negocio en función de los cuales establecían y se organizaban en torno de vínculos muy estrechos con los autores. Resultado de este tipo de experiencia fue la "delimitación de la figura del director literario o del asesor de publicaciones" $(173,175)$.

${ }^{11}$ En "Una biblioteca ibérica" anunciaban el proyecto editorial: "La Gaceta Literaria tiene el propósito de comenzar a publicar en plazo breve, con su marca editorial, una biblioteca ibérica.

Empezará acogiendo traducciones de libros catalanes, cuya dirección asumirá la empresa Catalonia, de Barcelona.

Probablemente serán obras de Bertrana, Soldevila y Puig i Ferreter de las primeras traducidas, el primer libro rubricado por La Gaceta Literaria. Un libro de poemas catalanes, La rosa y el laurel, del joven y delicado poeta Tomás Garcés, diario vigilante de las letras catalanas en La Publicitat". $L G L$. Año $1, \mathrm{n}^{\circ} 1$, febrero. 1927:1.

12 "Salutación" profería un llamado general: ¡Compañeros de letras: escritores, editores, lectores! ¡Salud! Y ayuda. ¡Fe! Y esfuerzo. ¡No abandonarnos diciéndonos adiós desde el puerto! ¡Embarcad! Cabemos todos”. LGL. Año1, nº 1, enero. 1927: 1. 
"novísima carabela" señalaba una propensión expansionista que veía en la lengua compartida la posibilidad de conquista de plazas editoriales americanas. Ortega diferenciaba claramente las tareas de la revista de las del periódico. Como periódico de las letras, $L G L$ venía a cumplir una función que aunaba la tarea difusora de la producción libresca a la de la literatura como "suceso"13 con una definición supranacional de la literatura española: "literatura en el sentido más amplio, española en un sentido enorme". Al mismo tiempo, la noción misma de literatura se ampliaba y desplazaba hacia lo impreso en formato libro. Así, $L G L$ tendría secciones fijas dedicadas a los libros -y no a las literaturas nacionales europeas- e inscribiría sus propósitos específicos ligándolos con la industria del libro y su necesidad de ampliación de mercados. ${ }^{14}$ Dadas las condiciones y desarrollo de una "vida literaria" "heterogénea y numerosa", era necesario un medio que la diera a conocer organizadamente y la volviera inteligible al púbico e incluso a los mismos escritores, quienes según Ortega andaban junto con el público "perdidos en medio de la selva impresa ejercitando un vago robinsonismo" ( $L G L$. Año1, ${ }^{\circ} 1$, enero. 1927: 1) [cursivas nuestras]. ${ }^{15}$ Como periódico, $L G L$ debía hacer visible a propios y ajenos de la República de las letras al "objetivar la vida de las letras", confiriéndole "presencia y perfil notorio como se ha conseguido en el siglo XIX

${ }^{13}$ Afirmaba: "Mas, libro y revista son obra -sólida o fluida. Queda todo un haz de literatura intacto en ambos: el hecho social e histórico de la obra y del autor. Queda, pues, íntegra la literatura como 'suceso', como acontecimiento real y viviente en medio de toda la realidad y de cuanto vive. Esta es la dimensión del fenómeno literario que sólo un periódico puede reflejar." $L G L$. Año1, nº 1 , enero. 1927: 1 .

${ }^{14}$ Esto se vincula también con la aspiración de difundir y legitimar fuera de España a las generaciones literarias e intelectuales, como forma de romper con el llamado provincianismo que aquejaba a la producción española. La transcripción que realiza $L G L$ de algunos fragmentos de Ramón de Basterra en la Información Española sobre LGL, muestra esos anhelos que son nombrados, justamente, con los términos "universalismo" y "meridiano":

"Rige desde entonces la hora continental en los horarios españoles. En la emisión sucesiva de Ramón Gómez de la Serna, este precipita cristales del espíritu universalista nuevo, anticipándose el meridiano de Madrid a los de París o Londres en ocasiones. La emisión postrera, finalmente, regentes de cuyo espíritu son Ernesto Giménez Caballero y Guillermo de Torre, capta el latido universal que recorre los nervios y los caminos del mundo. Son agentes del universalismo, tan grato a los del 900 como a los del 700". "Las generaciones de España en una nueva publicación oficial". LGL. Año 1, nº 4, febrero. 1927:5. Resaltado nuestro.

${ }^{15}$ Ortega sostenía: "El público no sabe nada de nosotros más que, si acaso, lo exorbitante, como de la jirafa sale el cuello superlativo. Pero nosotros mismos nos desconocemos los unos a los otros, mucho más de lo que se cree." LGL. Año1, nº 1, enero. 1927: 1. 
dar al Estado una corporeidad perfecta ante la conciencia de cada ciudadano. Y si esto lo ha logrado el periódico, también podrá lograr aquello" ( $L G L$. Año1, no 1 , enero. 1927: 1). ${ }^{16}$ Además, lejos de todo provincianismo, a semejanza del periódico a secas, debería "contar con la integridad del orbe literario español y sus espacios afines" evitando mutilar "la sociedad para hablar sólo de un rincón". (LGL. Año1, $\mathrm{n}^{\mathrm{o}}$ 1, enero. 1927: 1).

En acuerdo con las palabras tutelares de Ortega, $L G L$ tematizó la relevancia de estos medios. Precisamente, en un suelto llamado "El género literario de hoy: el periódico", subrayaba la importancia del periódico como órgano de la vida literaria respecto de la cual indicaba "se periodiquiza". ${ }^{17}$ Esta tendencia respondía a la velocidad que aportaban en las primeras décadas del siglo XX los nuevos medios de impresión, la consolidación del mercado empresarial del libro y la especialización de publicaciones (Martínez Rus 1023), y quedaba demostrada en la existencia de otras gacetas en Francia, Alemania, Italia. LGL se inscribía en esa línea, aunque reivindicando la experiencia de La República de las Letras de comienzos de siglo XX -llevada adelante por Luis Morote, Vicente Blasco Ibáñez, Benito Pérez Galdós y Rafael Urbano- como su antecedente español por sobre el francés y posterior de Les Nouvelles Littéraires. Esta afiliación nacional, conectada con el rechazo de la hegemonía cultural y editorial francesa sobre América y sobre España misma, constituyó uno de los argumentos vertebradores del "Madrid meridiano...". 18

\footnotetext{
${ }^{16}$ Así precisaba el qué consistiría esa objetivación: "A diferencia del libro y la revista, que son la literatura haciéndose, deberá mirar la literatura desde fuera, como hecho, e informarnos sobre sus vicisitudes, describirnos la densa pululación de ideas, obras y personas, dibujar las grandes líneas de la jerarquía literaria siempre cambiante, pero siempre existente." $L G L$. Año1, nº 1, enero. 1927: 1.

17 'La vida literaria se 'periodiquiza'. El periódico se 'literatiza'. Causa: il tempo prestissimo en que hay que vivir. 'Periódico y lectores de periódico es la característica de nuestro tiempo'. Así lo ha expresado Paul Valéry a su entrevistador, Radennacher, en la famosa visita que Valéry acaba de hacer a Alemania, como embajador de Paz y de Letras. Como "minervista". LGL. Año1, no 2, enero. 1927: 5 .

18 “Los periódicos de las letras. El antecedente de España”. $L G L$. año 1, n 3, febrero. 1927: 1. En este escrito, LGL responde a Les Nouvelles Littéraires en cuyas páginas se celebraba, irónicamente, que España tuviera su publicación quincenal.
} 
El énfasis en la relación entre periódicos de letras y mercado del libro ocupó el centro de la comunicación del director de $L G L$ en la Conferencia Nacional del Libro el 4 de marzo de 1927, publicada completa en el $n^{\circ} 7$ de abril de ese año, en la que Giménez Caballero se dirigía a editores, libreros, papeleros e impresores para convocarlos a participar del proceso de difusión del libro. ${ }^{19}$ A juicio de Giménez Caballero era urgente contribuir "a realzar la eficacia de las publicaciones periódicas sobre las letras en España" puesto que constituían "[el] gran motor interno del libro" (LGL. Año, no 4, abril. 1927: 1). Este apoyo, que pedía para su propio periódico, no consistía solo en lo económico, sino también en "[d]atos, bibliografía de la quincena, envío de libros, de noticias anticipadas, de todo ese material que solo ustedes pueden proporcionar al escritor". En el mismo sentido, otras colaboraciones afirmaban la necesidad de "expansión periodística" de las letras instando a la prensa diaria a la creación de secciones fijas que propagaran y pusieran al corriente sobre la producción editorial, que funcionaran como "correo literario" brindando "[i]nformación cotidiana amplia, minuciosa y preferentemente objetiva de todas las novedades literarias que salen al mercado" ( $L G L$. Año, $\mathrm{n}^{\circ} 4$, abril, 1927, 1). ${ }^{20}$ Así, por ejemplo, Giménez Caballero anteponía la obligación de $L G L$ de informar y enterar a los lectores sobre todo lo editado, a la necesidad parcial de la militancia estética propia de las revistas, identificadas con gestos selectivos y gustos específicos. ${ }^{21}$ Otros escritos se focalizaban en la circulación, venta y

\footnotetext{
${ }^{19}$ Los epígrafes indicaban la función articuladora del "periódico de las letras" en la propagación del libro. Algunos de esos epígrafes/ apóstrofes fueron: "Editores: Anunciad en La Gaceta Literaria. Es vuestro órgano", "Editores: El anuncio en La Gaceta Literaria es el más barato y eficaz", “¿Editores: La Gaceta Literaria es vuestro periódico, anunciad vuestros libros!”.

20 "La información literaria en los periódicos". $L G L$. Año 1, $\mathrm{n}^{\circ}$ 6, marzo. 1927: 1. Otros escritos como "Política cultural" de Lorenzo Luzuriaga insisten en la idea de expansión, que otros nombran como dilatación, amplitud de onda, etc., para señalar un objetivo y describir la situación editorial. Afirma: "La palabra que acaso convenga más a esa inquietud reinante es ésta: expansión. El trabajo cultural hispano de los últimos decenios ha empezado a dar sus frutos, y cada vez se siente más la necesidad de sacarlo a luz del mundo. Sólo que esto supone una enorme responsabilidad, de la que hemos de hacernos solidarios todos: escritores, profesores y técnicos". $L G L$. Año1, $\mathrm{n}^{\circ} 2$, enero. 1927: 5.

${ }^{21}$ En conversación con Juan Ramón Jiménez explicaba: "Nosotros tenemos deberes de información. Y no gustos de selección. Haga usted la selección. Nosotros daremos la noticia. Haga usted la revista que le postula su particular biología". "Manías de los escritores". $L G L$. Año 1, nº 8, abril. 1927: 1 .
} 
consumo urbanos de los diarios, revistas y periódicos como lectura previa y decisiva que "prepara a la gente a ver si se decide a entrar en las librerías" ( $L G L$, Año $1, \mathrm{n}^{\mathrm{o}} 15$, agosto. 1927: 1). ${ }^{22}$

Estas ansias difusoras y propagandísticas de las letras encarnaron en la "arquitectura" y en varias secciones de $L G L$. Geraldine Rogers (1) en la línea de Hamon, ${ }^{23}$ ha pensado y definido las publicaciones periódicas como "dispositivos de exposición, arquitecturas de aparición periódica que disponen de manera conjunta lo visible y lo legible" y que, como "construcciones destinadas a mostrar", ponen a la vista y dan a leer, acciones cuya dimensión performativa es insoslayable. ${ }^{24}$ En el caso de $L G L$, muchas de sus secciones estuvieron fundadas en una idea de la difusión editorial ligada con lo visual, empeño perentorio que algunas intervenciones hicieron explícito de manera poco sutil al afirmar la urgencia de "exponer y meter por los ojos al público" 25 la producción española. Así, para el caso de los libros de autores americanos "Libros americanos" cambió su subtítulo de "Crítica de Libros" (una función que estaba destinada a la revista y no al periódico) por "Escaparate de libros", la vidriera donde se exhibían, y que los agrupaba a su vez en términos de mostradores o anaqueles nacionales. "Manías de

\footnotetext{
22 "Revistas y periódicos. Lo que ellos venden y lo que la gente compra" es el título del escrito firmado por José Venegas que destaca la aspiración de $L G L$ de difundir ampliamente la literatura. Así lo indica Venegas desde comienzo: "La Gaceta Literaria ha querido situar la literatura en medio de la calle. No sé quién decía que él no iba a salir a la calle con sus obras a disputarle el arroyo a no sé quién. Con decirlo demostraba que era incapaz de conseguir la atención de los transeúntes. Y esto es lo interesante. La gente, el público, la masa no tendrán muy buen gusto, pero hay que salir a su conquista. Si, al salir de casa por la mañana, o al volver a la hora de la cena, tuviese uno que buscar una librería, entrar en ella, aguardar silencioso junto al mostrador y pedir, por último, al dependiente el diario de la mañana o el de la noche, ¿cuántos periódicos se venderían en Madrid?". El artículo revisa y, prácticamente, censa la prensa madrileña. LGL. Año 1, $\mathrm{n}^{\mathrm{o}}$ 15, agosto. 1927: 1. Resaltado nuestro.

${ }^{23}$ Rogers retoma Expositions. Littérature et architecture au XIXe siècle de Philippe Hamon de 1989.

${ }^{24}$ Según Rogers "[p]ensar las publicaciones periódicas como construcciones destinadas a mostrar (poner a la vista, dar a leer) implica en primer lugar atender a una dimensión performativa que puede o no coincidir con las declaraciones explícitas. Abre la pregunta acerca de qué y cómo en ellas se expone, se subexpone o se sobreexpone, y lleva a considerar la creación de revistas como modo de intervenir en el reparto de lo visible y lo legible en la esfera pública y en el mercado de bienes simbólicos" (Rogers 1).

${ }^{25}$ Las palabras pertenecen a "Preliminares. Ante la exposición del libro argentino-uruguayo en Madrid" de Guillermo de Torre, escrito que será analizado en el segundo apartado del trabajo. $L G L$. Año 2, no 39, agosto. 1928: 1.
} 
los escritores" daba a conocer curiosidades de la personalidad de ciertos autores colocando en el centro de la nota la fotografía del autor elegido, ${ }^{26}$ de modo que imágenes y detalles iban configurando otra forma de publicidad que, junto con la información sobre premios, editoriales, entrevistas, encuentros, propagandas y avisos de libreros, impresores, agencias de noticias, acontecimientos institucionales; mostraba y daba espesor a la literatura en su dimensión material y social. $L G L$ se preocupó por las formas de sociabilidad y promovió cenas, "de periodicidad discontinua [que] no tendrán otro fin que el de agrupar libremente los elementos que andaban dispersos por nuestro mundo intelectual"; estas cenas se distanciaban de forma explícita de los banquetes, en tanto no proponían rendir homenaje a ninguna personalidad sino que se convocaba especialmente "a los editores, a los amigos del libro, e incluso a los lectores" para llevar adelante el “intercambio de noticias" concernientes al libro (Año 1, n 9, mayo. 1927: 1). ${ }^{27}$ Por otro lado, en consonancia con aquella función de correo prescripta por algunos actores y conjugándola con la comunicación visual, algunas secciones compartieron el nombre de "Postales" declinado geográficamente. Postales Ibéricas -que incluían Portugal- y de regiones particulares de España que incorporaban otras

${ }^{26}$ Entre las más famosas de esas fotografías se encuentra la del propio Ortega y Gasset en su moderno automóvil.

${ }^{27}$ En tal sentido, el periódico promovió la realización de encuentros para reforzar el intercambio de "noticias" literarias y como forma de aglutinar a los actores vinculados con el libro.

"El sábado, 7 de mayo, se celebrará la primera cena organizada por La Gaceta Literaria.

Estas cenas, de periodicidad discontinua, no tendrán otro fin que el de agrupar libremente los elementos que andaban dispersos por nuestro mundo intelectual, tras la disolución del Pen Club y en ausencia de otros organismos de convivencia literaria, junto a una mesa puesta.

Las cenas de La Gaceta Literaria no serán banquetes. Pues faltará el homenaje a alguien y el precio alto del cubierto. Convivencia, cordialidad, unas pocas voces, unos cuantos chistes, un buen número de saludos y apretones de mano. E intercambio de noticias principalmente. Por eso convocamos, no sólo a escritores y artistas, sino a los editores, a los amigos del libro, e incluso a los lectores.

Y por eso inauguramos nuestra primera cena del 7 de mayo con un Concurso de Noticias Literarias (reales y fantásticas), con premios a las tres más sensacionales. Las noticias podrán ser enviadas por escrito, o pronunciadas solemnemente de sobremesa. La lectura de las escritas correrá a cargo del lector oficial, señor Vighi.

La cena se celebrará a las nueve y media de la noche en 'El Oro del Rhin' (plaza de Santa Ana, Madrid). Las tarjetas, al precio de 7,50 pesetas, podrán recogerse en dicho establecimiento, en el Ateneo, en la Librería Meléndez (calle de Cedaceros, 12) y en la redacción del periódico, calle de Recoletos, 10, hasta el día 5 a las nueve de la noche". $L G L$. Año 1, nº 9, mayo. 1927: 1. Resaltado nuestro. 
lenguas del país ${ }^{28}$-Vasconia, Castilla, Cataluña, Asturias, Levante-, "Postales americanas", "Postales rusas", "Postales internacionales" (alemanas, francesas, inglesas), "Postais de Lisboa". La idea de postal implicaba además un interés por los lectores a quienes se dedicaba el envío, y ponía el acento en la inmediatez y novedad respecto de lo que informaba, ofreciendo una vista, panorámica o particular. Aunque esas postales fueron sobre todo literarias, no solo incluyeron obras, ediciones, concursos y autores literarios: las postales versaban también sobre pintura, música, aspectos culturales regionales ligados con cierta idea de representación; en relación con las letras, esas postales iban componiendo una geografía editorial y literaria a partir de otras secciones de difusión que también ponían énfasis en lo visual y que reforzaban palabras como "mapa" $\left(\mathrm{n}^{\circ} 3, \mathrm{n}^{\circ} 7\right)$. En "Postales americanas", $L G L$ explicitó su preocupación inaplazable por las letras hispanoamericanas; trató de darlas a conocer en otras secciones como "Folletón bibliográfico" ("De Re americana"), "Memoranda de revistas americanas" y, desde sus inicios, contó con un espacio, "Libros americanos", especialmente dedicado a la producción libresca de sus excolonias. Guillermo de Torre participó también de ese espacio de difusión; unos pocos meses después de su polémico escrito y como corresponsal en Buenos Aires, dirigiría la sección "Gaceta americana" en cooperación desde Madrid con Benjamín Jarnés, y se ocuparía sobre todo de literatura argentina, especialmente porteña.

\section{España habla con los editores de Buenos Aires}

Guillermo de Torre fue el autor del editorial del $\mathrm{n}^{\circ} 8$ de $L G L$ de abril de 1927 que provocó las respuestas (airadas, risueñas y burlonas) de Martín Fierro (Buenos Aires, 1924-1927), revista identificada con la vanguardia porteña de esos años y que también se hizo llamar periódico. Es conocida la historia de ese

${ }^{28} L G L$ se refiere a sí misma como "admisora de una pluralidad de lenguas peninsulares". "Las lenguas en el periódico. Por la pluralidad a la unidad". $L G L$. Año 1, no 2, enero. 1927: 1. 
intercambio. ${ }^{29}$ Cabe señalar que en la misma página de aquel editorial, que ocupaba el espacio más extenso, se publicó "Tras la conferencia del libro". Se trata de un texto sin firma que, unido a otros previos como el de Giménez Caballero leído en la Conferencia o la posterior conversación de Guillermo de Torre con Alfonso Danvila, de "Transeúntes literarios", ${ }^{30}$ o los escritos en que recogían la mirada de los editores nacionales, organizan una intervención sostenida del periódico alrededor de los diversos aspectos del "problema del libro", que era, en efecto, el foco del interés que "Madrid meridiano intelectual de Hispanoamérica" moduló en los términos ya conocidos. "Tras la conferencia del libro" distaba de ser una crónica: amplificaba la importancia capital de la Conferencia del libro, y hacía del editorial de Guillermo de Torre un texto decididamente orientado por ese acontecimiento institucional y fundado en las discusiones que allí habían tenido lugar. De ese modo, en "Madrid meridiano...", luego de los deslindes respecto de los legítimos intereses de España sobre América, de Torre interpelaba como escritor a sus pares nacionales y americanos, planteando como eje de la discusión literaria la obligación de conocimiento intelectual mutuo, en función del objetivo comercial de aumentar la exportación de libros y revistas peninsulares al continente americano. "Tras la conferencia del libro" centraba su interés en los agentes ligados con la producción y la distribución, y, con una retórica de queja, pasaba revista a las ausencias de editores y escritores, siendo la más importante de entre los últimos,

${ }^{29}$ Sara Bosoer sintetiza algunas de las problemáticas presentes la revista Martín Fierro en ese debate. Afirma: "Si bien la polémica del 'meridiano' problematiza la conexión entre el proceso de autonomización del campo cultural, la conformación de las identidades nacionales y el afianzamiento de un mercado cultural transoceánico se instaló en la historia literaria, centralmente, como un episodio en torno al problema de la lengua, y su relación con la identidad cultural y las vanguardias, tensiones que por supuesto registra. Los discursos en sus búsquedas de fundamentación articulan las preocupaciones y los temas de la década: la lengua, el mercado, la autonomía política y cultural respecto de la península, la cultura 'nacional', la inmigración, la vanguardia literaria, la ciudad, el americanismo, entre otros". La vanguardia 171.

30 “Transeúntes literarios" De Torre le preguntaba textualmente :“- ¿Cree usted -interrogamos- que no todo es buena ilusión nuestra; que, efectivamente, las relaciones intelectuales de España con América -más concretamente con la Argentina- han progresado de modo extraordinario en estos últimos años, y que se intensificará aún más este favorable acercamiento?

-Sí -nos responde Danvila-. Considero que en los últimos diez años esa amistad ha página progresado considerablemente, pero que puede hacerlo mucho más, mediante el conocimiento recíproco de nuestros respectivos valores. Allí no se conocen muy bien los nuestros, pero aquí se ignoran los suyos, salvo dos o tres nombres." $L G L$. Año 1, nº 12, junio. 1927:1. 
la de Nicolás María Urgoiti, dueño de la Papelera Española, de los diarios El Sol y La Voz, y quien desde 1914 “controlaba la sociedad Prensa Gráfica que agrupaba las revistas ilustradas Nuevo Mundo, La Esfera y Mundo Gráfico" (LGL. Año 1, no 8, abril. 1927: 1). ${ }^{31}$ Como ya señalé, además de hacerlo en este escrito, $L G L$ destacó la importancia institucional de la Conferencia y sus páginas reprodujeron la voz de los editores, destacando las opiniones de algunos de ellos como punto de partida para hacer un estado de situación y consignando las posibles líneas de acción. Así, por ejemplo, publicó el análisis de Nicolás María Urgoiti, junto con las observaciones de Gustavo Gili, Martínez Reus, Antonio Royo Villanova, José Antonio de Sangróniz.

Eslabón básico -aunque escasamente recordado- de la "serie discursiva global" "sobre el libro español en América [tendiente] a apuntalar ideológicamente los reiterados y fracasados intentos editoriales por monopolizar o [...] disputar los mercados lectores de América" (Falcón 50), fue la iniciativa de Guillermo de Torre de llevar adelante una serie de entrevistas a los editores porteños Samuel Glusberg, Manuel Gleizer, Juan Roldán, Jacobo Samet, Pedro García, que LGL publicó en ese orden, como estrategia de promoción de la mencionada exposición del libro argentino-uruguayo en Madrid para 1928, organizada por $L G L$ y coordinada por el editor Juan Roldán. ${ }^{32}$ Esta iniciativa -que es en rigor una encuesta a editores y por eso mismo es novedosa- vale como forma misma de acercamiento entre España y Argentina, como diagnóstico sobre la disposición argentina a religarse ahora editorialmente con España, sobre las posibilidades efectivas de esos lazos y como propuesta meridiana de organización de un gran "consorcio editorial argentino" y una red de distribución librera con centro en Madrid, cuya eficacia presente era puesta en duda por algunos de los argentinos. Fundamentalmente esta encuesta vale

\footnotetext{
${ }^{31}$ Se lo nombra como uno de los "capitanes del libro español"-n ${ }^{\circ} 11,1927-;$ se le dedica un artículo "Las editoriales españolas" que repasa la labor de Espasa Calpe- n 12, 1927-. A la ausencia de Urgoiti se agregaban los de otros “editores tan significados como Domingo Barnés, de La Lectura. De don José Ruiz Castillo, fundador de la Biblioteca Nueva. De Rafael Caro Raggio. Del librero León Sánchez Cuesta. De Saturnino y Rafael Calleja...” LGL. Año 1, nº 8, abril. 1927: 1.

32 LGL había realizado otras exposiciones ibéricas: catalana y portuguesa. Esta del libro argentinouruguayo era pensada como corolario. "Preliminares". LGL. Año 2, no 39, agosto. 1928:1.
} 
también como expresión de una política del libro por parte de los editores españoles en la conquista de plazas americanas, quienes según Fabio Espósito constituyeron una intrincada red junto con libreros, comisionistas, escritores, periodistas, hombres de negocios, políticos peninsulares y americanos que tomaron cuerpo en la "realización de misiones comerciales y viajes, en la difusión de revistas ilustradas, así como en la participación y organización de ferias, encuentros de empresario, congresos y conferencias" (518-519). Cabe señalar la relevancia de la figura de Guillermo de Torre en relación con esa política del libro, tanto desde su revista madrileña y de otros medios en los que colaboró desde Buenos Aires como corresponsal (El Sol, Revista de Occidente, Revista de las Españas), como en cuanto a las actividades que proyectó, y llevó adelante desde su llegada a Buenos Aires en septiembre de $1927^{33}$ varias conferencias en la Asociación Amigos del Arte y en la entonces llamada Facultad de Filosofía y Letras de La Plata, una muestra del libro español, la propuesta a las autoridades argentinas y a "los principales libreros de esta plaza la creación de una gran librería en Madrid, dedicada especialmente a acrecentar la expansión del libro", según indicaba una nota de la prensa porteña titulada "Guillermo de Torre, escritor español de vanguardia y sus proyectos a realizar en Buenos Aires", publicada inmediatamente después de su arribo. ${ }^{34}$ Como se verá, este plan sería otra de las motivaciones de su

33 LGL dio cuenta de la planificación de los reportajes a los editores por parte de de Torre. En "Guillermo de Torre, en Buenos Aires", consignaba: "En breve reanudará su colaboración a base de temas americanos, anunciándonos un reportaje sobre Rojas Paz y algunos editores bonaerenses". LGL. Año 2, no 28, enero. 1928:1.

${ }^{34}$ Según La Prensa de Torre "[p]royecta dar algunas conferencias sobre las literaturas europeas de vanguardia, sobre el romanticismo español, sobre Góngora, sobre la nueva generación española posterior a Ortega y Gasset y Gómez de la Serna, etcétera. Será, mientras dure su permanencia en la Argentina, corresponsal del importante diario madrileño El Sol, que le ha encargado una serie de artículos sobre este país. Igualmente escribirá sobre lo que aquí vea y observe para la Revista de Occidente, para la Revista de las Españas, publicación que dirige el duque de Alba, y para $L a$ Gaceta Literaria, de que es fundador, y respecto a la cual nos dijo que ha obtenido un éxito, aún económico, que no era por cierto esperado". 16/09/1927. Había llegado el 14/09/1927.

En un suelto sin fecha de un diario porteño que da cuenta de su llegada y de los propósitos intelectuales es posible leer el anticipo de lo que publica más tarde en "Preliminares".

"Guillermo de Torre, escritor español de vanguardia y sus proyectos a realizar en Buenos Aires" [...] De los escritores de la nueva generación literaria [dice Torre], se destaca en España E. Giménez Caballero, director, fundador conmigo de La Gaceta, cuya última obra, Carteles, conteniendo artículos de críticas periodística y ensayo realizados en original forma de composición tipográfica ha logrado gran aceptación [...]. 
encuesta a los editores y, ligado con la anunciada exposición de noviembre en Madrid, constituiría su aspecto más relevante; la encuesta sería anunciada en "Preliminares", la nota con que de Torre presentó la iniciativa en $L G L$.

"Preliminares" se publicó en el no 39 de agosto de 1928, ${ }^{35}$ un mes antes de la Primera Exposición del libro de Buenos Aires, cuyo principal organizador y promotor era el primero de los editores encuestados, Samuel Glusberg. El texto relegaba la polémica con los martinfierristas a un pasado inmediato al que pretendía olvidado, en términos de disputas culturales, salvo para extraer de él múltiples lecciones sobre el fondo de la cuestión que, según sus propios términos, nunca había sido literaria sino editorial, más precisamente de distribución. ${ }^{36}$ Esas lecciones debían ser tomadas en cuenta -sobre todo- por los países americanos que tenían que conocerse mutuamente con el fin de verse en términos "continentales" antes que nacionales, desde una perspectiva "menos localista y restringida" (contrariamente a España) que sumada a un conocimiento seguro de los gustos y preferencias de un público ampliado, habilitara la circulación fluida y más efectiva de los libros, prerrequisito para su difusión europea. Era allí donde, según de Torre, España debía

Guillermo de Torre va a pronunciar varias conferencias en Buenos Aires, a realizar-se en la Asociación Amigos del Arte y en las Facultades de Filosofía y Letras de La Plata, que versarán sobre literatura moderna, historia retrospectiva y un estudio sobre la obra de Góngora, sobre la que ha estudiado profundizando mucho.

Proyecta gestionar una muestra del libro español, a realizarse en igual forma que la actual, del libro italiano, mediante el apoyo oficial que se logró para ésta.

El libro argentino está muy poco difundido en España, y contadas librerías distribuyen las obras de nuestros literatos: en cuanto a las novedades literarias que de España llegan a Buenos Aires ha podido deducir de Torre, por conocer acciones habidas, que se distinguen más por su cantidad que por su calidad.

En consideración de la escasa difusión del material argentino en la península va a proponer a nuestras autoridades y a los principales libreros de esta plaza la creación de una gran librería en Madrid, dedicada especialmente a acrecentar la expansión del libro.

Expresa Guillermo de Torre que esta empresa -que difícilmente puede ser acometida por particulares-sería de un incalculable beneficio para el acercamiento intelectual hispanoamericano, esperando poder llevarlo a feliz término". (García 6).

${ }^{35}$ Todas las citas corresponden a la página 1.

${ }^{36}$ De Torre aclaraba: "En el fondo -afirmé- todo este pleito inevitable y salutífero entraña más bien un problema editorial y librero que una cuestión literaria. La supuesta hegemonía intelectual hispánica, cuya intención nos han atribuido hiperbólicamente, y la virulenta reacción provocada en la epidermis susceptible de ciertos espíritus lógicamente puntillosos de su independencia literaria y fieramente jactanciosos de ser 'ellos', no pasa de reducirse a un choque de ininteligencias mutuas, que se disipará merced al conocimiento, como todos los equívocos y 'quid pro quos"'. LGL. Año 2, n 39, agosto. 1928:1. 
desempeñar un rol fundamental en el trazado de esa "red de expansión librera hispano e interamericana" puesto que, argumentaba, "contrariado un axioma geométrico, la línea quebrada resultará más corta que la línea recta” en virtud de los costos elevadísimos de envío dentro de los países y del continente. Esto permitiría superar el "particularismo que padecen como autores, un poco asfixiados dentro de los estrechos límites en que hasta ahora se desenvuelve el libro argentino, sin amplios horizontes de expansión -salvo casos excepcionales-, y los resentimientos engendrados por ese 'insularismo' editorial". En cuanto a la responsabilidad de España respecto de la falta de conocimiento de la producción americana, criticaba severamente a las instituciones españolas que, como la Cámara del Libro de Madrid, "no ha tratado nunca de crear un suplemento bibliográfico hispanoamericano, un boletín donde se registren al día todas las novedades bibliográficas de este continente, editadas en lengua castellana" (1).

Como señalé, las respuestas de Samuel Glusberg ( $L G L$, Año 2, $\mathrm{n}^{\circ}$ 40, agosto. 1928: 1) fueron las primeras de esa encuesta. Además de Babel, su sello editor, Glusberg llevaba adelante la revista La Vida Literaria, que como LGL tenía entre sus prioridades la "vida del libro" y la bibliografía; impulsaba la primera exposición del libro de Buenos Aires, y había realizado una exposición en Mar del Plata como su paso previo. El intercambio pone en evidencia los énfasis diversos del encuestador y el encuestado. Así, mientras el editor consignaba "cuestiones espirituales" entre las razones de su interés por el mercado español, aunque le diera pérdida, de Torre, que evidentemente no compartía algunas de sus opiniones esboza un "gesto de extrañeza"-, anteponía la necesidad de "conocer la verdadera temperatura del nuevo espíritu argentino" y poniendo en acto la necesidad de mutuo conocimiento remarcaba por sobre el desacuerdo que "[1]o esencial, por ahora, es conocer cómo se producen opiniones de este diapasón". Una de ellas era hacer conocer la literatura de su sello editorial en España. Glusberg acordaba con la propuesta de crear en España una sede propia del libro argentino en Madrid, "conviene intentar un gran centro editorial en Madrid, a la manera de la Maison du Livre, de París. De realizarse esta iniciativa seriamente y no con fines raciales, 
sentimentales, etcétera, la editorial Babel daría su apoyo en todo sentido". A la pregunta por el área de difusión del libro argentino, señalaba que los suyos salían de Buenos Aires y del país aunque esta difusión no suponía necesariamente encontrar lectores; al mismo tiempo insistía en su imposibilidad para competir con los costos y calidad del libro extranjero y de las traducciones. Guillermo de Torre pensaba en estrategias "concretas", y no solo diagnósticos, como por ejemplo procedimientos "para obviar las dificultades del cambio, estableciendo un precio medio para España y los países americanos de habla española"; Glusberg exponía su modalidad: encargar segundas ediciones (1000 ejemplares de los que se vendían menos de 200) en Madrid a Espasa Calpe, que podrían ser consideradas ediciones españolas de libros argentinos, aunque esto no le había dado muchos beneficios.

Un mes más tarde, en septiembre de 1928 ( $L G L$, Año 2, nº 41, septiembre. 1928:1), respondió Manuel Gleizer, a quien se definía como el "editor por excelencia de la nueva literatura argentina", sobre todo novelistas y poetas, reuniéndolo con Samet y Glusberg como "los pilares más sólidos del edificio editorial argentino", junto con los españoles Roldán, García y Menéndez. De Torre destacaba sus otros emprendimientos: la Biblioteca Médica, la colección de clásicos argentinos, la Galería de educadores -además de la colección Índice en la que había publicado a Leopoldo Marechal, Eduardo Mallea, Enrique González Tuñón, Jorge Luis Borges, y Francisco Luis Bernárdez. Como Glusberg, Gleizer afirmaba que el mercado del libro español, en el que de hecho participaba y a pérdida, le interesa por razones culturales, no comerciales. Ante la pregunta por el establecimiento de la "gran entidad librera argentina en España" con el concurso estatal, Gleizer se mostraba contrario a ella, en tanto veía que los beneficios correrían sobre todo por el lado español. De esa forma, consideraba que la ayuda oficial -consistente por ejemplo en el funcionamiento efectivo de la Comisión Protectora de Bibliotecas- debían recibirla los editores argentinos, a los que juzgaba desamparados en su quehacer intelectual.

El tercero en responder, en octubre de 1928 ( $L G L$, Año 2, nº 44, octubre. 1928:1) fue el español Pedro García, cuyas figura y posición en el comercio de 
libros en Buenos Aires diferían notoriamente de las de los dos encuestados anteriores, y a quien de Torre decidió no someter "al cuadriculado de las rejillas del cuestionario habitual" que dejaba para los porteños. Procedente de una familia librera -sus hermanos desarrollaban su actividad comercial también Buenos Aires; él tenía su local en la calle Florida-, encarnaba la imagen del librero-editor y aunaba popularidad y prestigio. De Torre lo nombraba como "príncipe triunfador", "domador del éxito", "profesor de energía" y sobre todo como "arquetipo del español transatlántico". A de Torre le interesaba principalmente por su experiencia y conocimientos de "todos los problemas del libro americano y español, localizados en Argentina". Entre sus numerosas observaciones sobre el consumo del libro editado en Argentina, García señalaba la posición desventajosa del libro estrictamente literario que, a diferencia de los libros históricos, de investigación, didácticos o científicos, casi no se vendía en otras ciudades del continente. Consideraba como una de las razones fundamentales de esa situación el hecho de que, en su mayor parte, los editores no publicaran libros inéditos, orgánicos sino recopilaciones de escritos ya dados a conocer en revistas y de muy discutible calidad. Por tanto, para García el punto central a considerar para la difusión en otros mercados debía ser el de "cuidar la materia prima: contenido" diferenciando lo que se pensaba como libro de la producción destinada a abastecer los magazines semanales. Al mismo tiempo, consignaba que el libro más vendido en América era el impreso en España que, por sus menores costos de producción, resultaba más beneficioso para autores y editores. García descreía de las posibilidades efectivas del establecimiento de la gran entidad librera en España, a base de un consorcio entre los editores argentinos, en tanto no existían instituciones que aglutinaran y organizaran colectivamente a los editores, "todavía no contamos siquiera con una Cámara del libro...".

Quien respondió a nombre de Juan Roldán y cía. ( $L G L$. Año 3, nº 49, enero. 1929: 6) en la sección "Gaceta Americana”, fue su socio, el Sr. Bernabé. Se trataba también de libreros-editores, con local en calle Florida, la librería La Facultad, especializada en la producción didáctica, jurídica y universitaria, en menor medida 
literaria, "uno de los escaparates más visibles del libro español en Buenos Aires", y "una de las primeras casas que iniciaron el auge actual del libro argentino, emprendiendo la edición de obras fundamentales y costosas". Para paliar el desconocimiento mutuo de la producción literaria de las naciones americanas, proponía su difusión en la prensa por los grandes centros intelectuales, ya que a su juicio libros había de sobra, no así lectores y por tanto compradores. De tal modo, antes que una entidad librera argentina en Madrid, era necesario seguir apostando a la propaganda, por ejemplo, en su caso, a través de la publicación de un "Boletín de novedades mensuales", de la producción nacional y española.

A diferencia de los libreros-editores de La Facultad, Jacobo Samet ( $L G L$. Año 3, no 54, marzo. 1929: 7) apostaba al libro literario y se mostraba muy entusiasta respecto de sus posibilidades en las zonas "selectas" del publico porteño, no obstante reconocía las diversas dificultades que en general afectaban a la producción del libro, que no era una rama comercial de larga data en el país. De Torre lo caracterizaba como el editor más joven -hacía solo cuatro años había iniciado su labor; Samet había publicado primeros libros interesantes y ponía el esfuerzo en descubrir y revelar autores juveniles ("Tuvo una participación no pequeña en las gestas y combates de la vanguardia argentina, publicando libros, auspiciando revistas y estimulando vocaciones"). ${ }^{37}$ Se quejaba de "proteccionismo al revés, ejercido por nuestras leyes, y merced al cual entran en el país, libres de todo gravamen, las publicaciones extranjeras, mientras pesan considerables impuestos sobre el papel y sobre todos los materiales a emplearse en la confección del libro argentino". Consideraba que el área de difusión del libro argentino - el más prestigioso y leído de todos los libros hispanoamericanos- debía abarcar toda

${ }^{37}$ Samet mismo se autodefinía como un editor literario moderno: "Cuando hace cuatro años -nos dice- lancé al mercado el primer libro (Prismas, de González Lanuza) estaba yo, más que nadie, lejos de prever la posición que ocuparía luego entre libreros y editores. ¡Quién me hubiera dicho que en aquel lanzamiento, y en la defensa verbal y periodística que después hube de hacer del libro, estaba contribuyendo aquí a uno de los movimientos literarios más importantes de la historia! En aquellos momentos desafié el ridículo y luché como pude contra la incomprensión y el empecinamiento. Desde entonces mi casa es la casa de las izquierdas y de las vanguardias. El triunfo, ya indiscutible, de las nuevas tendencias literarias me toca directamente y me enorgullece. Uno a uno he ido conquistando a los lectores para los poetas de la nueva generación". 
la América española. Algunas de las mayores dificultades eran la posición excéntrica de Buenos Aires, el excesivo individualismo de los editores, la inexistencia de una Cámara del libro argentino, cuyas posibilidades de prosperar veía improbables. Acordaba con la iniciativa de distribución propuesta por de Torre y la consideraba como oportunidad de una relación menos declarativa y más concreta que favorecería el conocimiento recíproco de mercados y lectores, que era lo que no abundaba. Y por supuesto, apoyaba la exposición del libro argentinouruguayo en Madrid.

La encuesta editorial iniciada con el escrito "Preliminares" de Guillermo de Torre en agosto de 1928 concluyó con la intervención de otro español, Julián Urgoiti, ${ }^{38}$ delegado de Espasa-Calpe en Buenos Aires desde 1922. ${ }^{39}$ De Torre argumentaba que una voz como la de Urgoiti permitiría "mostrar los aspectos que ofrece la expansión del libro argentino relacionados con la difusión del libro español en esta República" (5). El hecho de que las opiniones argentinas estuvieran en medio de las de los dos españoles enfatizaba el lugar privilegiado que Madrid pensaba para sí en ese diseño de los vínculos comerciales. Según de Torre, los 6 años al frente de Espasa-Calpe, le habían confirmado a Urgoiti la necesidad de realizar una tarea "acorde a los editores, con los intereses y con los autores nacionales, sumando y agregando esfuerzos, pero nunca excluyendo ni situándose marginalmente" (5). Urgoiti se referiría con especial atención a "los aspectos que ofrece la expansión del libro argentino en su relación con la difusión del libro español en Argentina" (5). Explicaba que hacía llegar el libro español a casi toda la Argentina, a pesar de las deficiencias en los medios de propagación entre los grandes centros culturales -Buenos Aires, Rosario, Córdoba, ávidos consumidores de publicaciones de minorías- y el interior, adonde llegaban y se vendían obras de interés más general. Indicaba también que, al menos para su sello editor, el libro

\footnotetext{
38 "Lo que dice un editor español en Buenos Aires: Julián Urgoiti, delegado de Espasa-Calpe". LGL. Año 3, n 55, abril. 1929: 5.

${ }^{39}$ Espósito señala que con Calpe se terminó definitivamente el predominio del libro francés en América. En 1925 se había fusionado con Espasa para comercializar la Enciclopedia Universal Ilustrada tanto en España como en América (532).
} 
francés y el italiano no significaban ya una competencia real. En cambio, a las ediciones peninsulares, sí podía restarles público el libro argentino; como forma de contrarrestar esta amenaza el editor peninsular tendría que evolucionar "hacia dominios más exclusivos -tal, verbigracia, el caso de las publicaciones de la Revista de Occidente-, o que, fomentando lo más general, [puede ofrecer] [...] una producción francamente económica y bien seleccionada". Señalaba las posibilidades que ofrecía una plaza como Buenos Aires en función de su doble condición de centro asimilador de la producción libresca y como:

[...] foco que irradia una parte no pequeña de la producción editora española, merced a la acción combinada que despliegan las cuatro o cinco casas depositarias de conocidas editoriales españolas, aparte de otros representantes, con el núcleo de libreros progresistas, toda cuya acción conduce a un resultado, si no brillante, (y es imprescindible usar con parquedad de los adjetivos), por lo menos discreto y promisor de cosas más halagüeñas. (LGL. Año 3, no 55, abril. 1929: 5)

Criticaba la llamada producción extensiva de los libreros españoles para exportación que, carente de todo análisis previo, llevaba a resultados desastrosos. ${ }^{40}$ En relación con el libro argentino en España, indicaba que su área de difusión era verdaderamente restringida porque carecía de una organización que la encauzara. Según Urgoiti podía ser España el centro difusor de la producción argentina, como podía serlo de "la de todo país americano, en general, merced a su tradición editorial, que la ha creado vínculos cordialísimos en todo el mundo hispanoparlante, y aun en los de idioma extraño". A estas razones, el representante de Espasa-Calpe agregaba los bajos costos de envío para las remesas de libros enviados desde España, garantizados por la Convención Postal Hispanoamericana.

${ }^{40}$ Sostenía: "El editor español, que mira seriamente a estos países, como factor ponderable en su cálculo de posibilidades de colocación del libro en ciernes, tiene el deber de pulsar si es oportuna la publicación, por lo que a esos mercados se refiere, y no tener la pretensión de que el público arrebate los libros cuando no se le ofrece lo que le interesa". 


\section{A modo de conclusión}

La revisión del contexto editorial de "Madrid meridiano..." a la luz de los fundamentos del proyecto editorial de $L G L$ como "periódico de las letras" junto con el análisis de las entrevistas a editores porteños permite mostrar un vínculo deseado de los escritores con el mercado editorial y, al mismo tiempo, enfatizar aspectos relevantes y específicos de las relaciones editoriales y literarias entre un lado y otro del Atlántico. Atender al concepto editorial de $L G L$ invita a revisar y a ampliar el archivo de la cuestión meridiana entendida como parte de una política literaria ligada con una política del libro. A ese archivo deberían incorporarse además de las entrevistas de Guillermo de Torre, los numerosos textos de $L G L$ sobre la difusión del libro -particularmente a su presencia en la prensa- y las discusiones sobre aspectos institucionales ligados con el comercio librero. En cuanto a las entrevistas, las preguntas que las organizaban insistieron, a partir de un agudo diagnóstico, en la necesidad urgente de difusión que, a nivel continental, se presentó como imperativo de un conocimiento "interamericano" y a escala transatlántica como "un mejor conocimiento recíproco" entre España y América fundamento de cualquier posibilidad de colocación de la producción editorial en ambos mercados- a través de estrategias variadas, entre otras, la creación de boletines bibliográficos y el sondeo de los gustos del público potencial. En sus respuestas, argentinos y españoles reconocieron la ausencia de una organización institucional americana en materia editorial (i.e. la inexistencia de una Cámara del Libro argentino o de catálogos de la producción nacional), y en menor medida española (la ineficacia de la Cámara del Libro de Madrid). A estas deficiencias institucionales los argentinos agregaron la dificultosa distribución, los costos elevados de producción de sus libros y las cuestiones cambiarias que los llevaba a comerciar a pérdida con España. Como propuesta de fortalecimiento de comercio librero español, "la creación de una gran entidad librera argentina -o suramericana- 
en Madrid, encargada de distribuir y propagar los libros de todo este continente" fue parcialmente aprobada en las respuestas; los argumentos vertidos por de Torre acerca de su necesidad son la prueba de la disimetría en el desarrollo editorial entre ambas partes y, por tanto, de la distribución de los beneficios económicos.

Si se tienen en cuenta el medio y el contexto de publicación de estas intervenciones, se torna evidente la nueva relación entre revistas y periódicos con los libros, que toma cuerpo en el "periódico de las letras" como medio de difusión donde se fragua una nueva relación entre escritores y mercado editorial. No solo no se desdeñaba la faz económica de los libros, sino que además los escritores asumieron más o menos explícitamente, la necesidad de construir un mercado para la literatura y la producción libresca, en el cual se distinguían y especializaban apuestas editoriales específicas. En las repuestas bonaerenses, a menos de un año de "Madrid meridiano...", el punto de interés desplazaba el foco de la lengua, en que se habían centrado los martifierristas, a los lectores, más allá de cómo se los caracterizara o definiera -"selectos", "cultos", "masa lectora", "público de librería”, "compradores"- cuya conquista era imperiosa. En cuanto al artículo editorial de Guillermo de Torre, razonar su lectura en el contexto de la revista -y en la misma página junto a "Tras la conferencia del libro"-, modifica su sentido -no ya como un texto que abre una polémica- sino como parte de otro corpus -aún no sistematizadodel cual forman parte central las conversaciones de Guillermo de Torre con los editores argentinos. 
CATEDRAL TOMADA: Revista literaria latinoamericana / Journal of Latin American Literary Criticism

Verónica Delgado

\section{Bibliografía}

La Gaceta Literaria, 1927-1932.

Albert, Mechthild. "La Gaceta Literaria, actor de una vanguardia transnacional”, Almacenes de un tiempo en fuga, ed. Hanno Ehrlicher y Nanette RißlerPipka. Aache: Shaker Verlag, 2014. 339-356.

Alemany Bay, Carmen. La polémica del Meridiano Intelectual de Hispanoamérica (1927). Estudio y textos. Alicante: Universidad de Alicante, 1998.

Bosoer, Sara Amalia. “Algo más que hispanismo -antihispanismo en la polémica por el meridiano: lengua, nación y mercado a fines de la década de 1920”. I Congreso Internacional de Literatura y Cultura Españolas Contemporáneas, 1 al 3 de octubre de 2008, La Plata. Los siglos XX y XXI.

<http://www.fuentesmemoria.fahce.unlp.edu.ar/trab_eventos/ev.301/ev.3 01.pdf $>$ . La vanguardia plebeya de Nicolás Olivari: mercado, lengua y literatura (1919-1929). Tesis de doctorado. 2012 〈http://www.memoria.fahce.unlp.edu.ar/tesis/te.765/te.765.pdf $>$

Bourdieu, Pierre. Intelectuales, política y poder. Buenos Aires: Eudeba, 2006.

Delgado, Verónica y Espósito, Fabio. “1920-1937. La emergencia del editor moderno".

José Luis de Diego, director. Editores y políticas editoriales en Argentina, 18802010. México-Buenos Aires: FCE, 2014. 63-96.

Di Tulio, Ángela. "Meridianos, polémicas e instituciones: el lugar del idioma". Historia crítica de la literatura argentina. Volumen 7. Rupturas. Celina Manzoni, directora. Buenos Aires: Emecé, 2009. 569-596.

Espósito, Fabio. "Los editores españoles en la Argentina: redes comerciales, políticas y culturales entre España y la Argentina”. Carlos Altamirano, director. Historia de los intelectuales en América Latina. II. Las 
aventuras de la "ciudad letrada" en el siglo XX. Buenos Aires: Katz, 2010. 515-536.

Falcón, Alejandrina. "El idioma de los libros: antecedentes y proyecciones de la polémica "Madrid meridiano 'editorial' de Hispanoamérica". Iberoamericana 37 (2010): 39-58.

Fernández Moya, María Inés. "La promesa del gran mercado del libro. Un siglo de editoriales españolas en Argentina (1908-2008)". XIII Seminario Complutense de Historia Económica. Madrid. 2010. S/D

García, Carlos. "Guillermo de Torre en Buenos Aires (1927): Literatura y negocios". <https://www.academia.edu/28018115/Guillermo_de_Torre_en_Buenos _Aires_1927_._Literatura_y_negocios $>$ Consultado 4/12/18.

Larraz, Fernando. Una historia transatlántica del libro. Relaciones editoriales entre España y América (1936-1950). Gijón: Trea, 2010.

Manzoni, Celina. "La polémica del Meridiano intelectual”. Joaquín Marco, editor. Actas del XXIX Congreso del Instituto Internacional de Literatura Iberoamericana. Tomo II (volumen I). Barcelona: PPU, 1994. 823-832. . "La polémica del Meridiano Intelectual y la internacionalización del debate en la vanguardia latinoamericana". Almacenes de un tiempo en fuga, ed. Hanno Ehrlicher y Nanette Rißler-Pipka. Aache: Shaker Verlag, 2014. 271-294.

Martínez Martín, Jesús. "La edición artesanal y la construcción del mercado". Jesús Martínez Martín, director. Historia de la edición en España 18361936. Madrid: Marcial Pons, 2001. 29-72.

Martínez Rus, Ana. "La industria editorial española ante los mercados americanos del libro 1892-1936". Hispania, LXII/3, 212. 2002. <https://doi.org/10.3989/hispania.2002.v62.i212.248>

Rogers, Geraldine. "Las publicaciones periódicas como dispositivos de exposición”. En: V. Delgado y G. Rogers. Revistas, archivo y 
CATEDRAL TOMADA: Revista literaria latinoamericana / Journal of Latin American Literary Criticism Verónica Delgado

exposición. Publicaciones periódicas argentinas del siglo XX, La Plata, Universidad Nacional de La Plata, 2019, en prensa.

Sarlo, Beatriz. "Vanguardia y criollismo: La aventura de Martin Fierro. Revista de Crítica Literaria Latinoamericana. Año 8, 15 (1982): 39-69. 